\title{
A proteção ao trabalho do menor
}

\author{
Suélen Shiguetomi Cordeiro da Silva ${ }^{1}$ \\ Lourival José de Oliveira ${ }^{2}$
}

\begin{abstract}
Resumo
Abordou-se 0 trabalho infanto-juvenil desde as suas origens até os dias atuais, bem como a evolução das normas de proteção a esse tipo de trabalho, demonstrando-se a importância das mesmas, no tocante aos cuidados de pessoas ainda em desenvolvimento. Foram expostas algumas das causas que fazem com que a exploração infantil e o trabalho irregular de adolescentes ainda persistam, evidenciado por dados obtidos através de pesquisas como o PNAD. Analisou-se a legislação brasileira que trata do assunto, especialmente no que se refere às proibições a determinados tipos de atividade, a idade para entrada no mercado de trabalho, os direitos dos jovens trabalhadores, autorização e incentivo para a formação técnico-profissional de adolescentes, através da aprendizagem. Indicou-se os legitimados na defesa pelos menores trabalhadores, demonstrando a importância dos mesmos, para a erradicação da exploração infantil. Concluiu-se pela necessidade de maior efetivação e cumprimento das respectivas leis, através da conscientização de toda sociedade, bem como das empresas, empregadores e maior fiscalização por parte do poder público.
\end{abstract}

Palavras-Chave: Trabal ho infanto-juvenil; Normas de proteção; Legitimação e Efetividade.

\section{Introdução}

O presente trabalho objetiva o estudo acerca das atividades laborais realizadas por menores, bem como as normas jurídicas de proteção aos jovens trabalhadores, e a aplicação das mesmas.

Partindo-se dos antecedentes históricos, bem como das primeiras medidas de proteção aos jovens trabalhadores, será demonstrada a importância da criação da Organização Internacional do Trabalho, cuja preocupação em eliminar o trabalho infantil e adolescente irregular, influencia seus países signatários, através de suas Convenções, fazendo com que estes produzam e aperfeiçoem suas regras acerca do tema, visando a garantia dos direitos de crianças e adolescentes, para Ihes possibilitar um correto desenvolvimento físico, psíquico, social, moral e educacional.

Acadêmica do 5o ano matutino do curso de Direito da Universidade Estadual de Londrina.

2 Doutor em Direito (PUC-SP); professor associado da Universidade Estadual de Londrina; professor da FACCAR; professor do curso de Mestrado em Direito da UNIMAR. 
Dentre estes países encontra-se o Brasil, que possui normas de proteção à infância e à adolescência presentes na Constituição Federal, Consolidação das Leis do Trabalho, Estatuto da Criança e do Adolescente, dentre outras legislações esparsas.

Entretanto, mesmo diante de tantas regras visando a preservação dos direitos de crianças e adolescentes, e a proteção destes no aspecto trabalhista, ainda existe um número muito grande de crianças e adolescentes inseridos em atividades econômicas do país.

Assim, da análise dos fatores determinantes para o trabalho precoce no Brasil, serão examinadas as principais legislações pertinentes a tal matéria, na tentativa de se explicar porque, diante de todo o aparato institucional existente, ainda persiste a entrada e ocupação no mercado de trabalho por crianças e adolescentes, quando deveriam estar voltados para sua infância, desenvolvendo sua formação e aprendizado, para somente após enfrentarem as responsabilidades financeiras e o mercado de trabalho.

Nesse sentido, a atuação de órgãos legitimados na proteção dos menores se faz essencial para que se consiga a efetiva concretização das normas de proteção ao trabalho do menor.

\section{Antecedentes}

0 trabalho de crianças e adolescentes existe desde épocas muito antigas, porém, a preocupação em protegê-los veio apenas em 1802 na Inglaterra, com o Moral and Health Act, após a Revolução Industrial, que evidenciou a precária condição das crianças trabalhadoras, totalmente desprotegidas (NASCIM ENTO, A., 2007, p. 980).

A partir de então, os demais países europeus, e depois americanos, dentre eles 0 Brasil - primeiro país da América Latina a fazê-lo, também passaram a regulamentar a questão do trabalho de menores, prevendo inicialmente limitações de jornada e idade mínima laboral, ainda que de modo bastante precário.

O Brasil passou a legislar sobre a proteção ao trabalho de menores em 1890, com o Decreto n. 1.313, apesar de nunca ter sido colocado em prática por falta de regulamentação. Somente com o Código de Menores, de 1927 é que regras como proibição do trabalho pelos menores de 12 anos, e do trabalho em período noturno àqueles com menos de 18 anos, puderam ser aplicadas (M ARTINS, A., 2002, p. 31). 
Outros Decretos foram editados, as Constituições, a partir de 1934 passaram a tratar da matéria, fazendo com que tais normas de proteção fossem evoluindo e se aperfeiçoando, até culminar com a Constituição de 1988, que previu o Princípio da Proteção Integral de Crianças e Adolescentes, em seu art. 227, cujo objetivo é o de resguardar a vida saudável e digna dos mesmos, proibindo sua exploração (BARROS, 2006, p. 524).

\section{Fatores determinantes para o trabalho do menor no Brasil}

Muito embora a existência de garantia constitucional para preservação das crianças e adolescentes, o trabalho infanto-juvenil persiste no Brasil, país que apresenta um dos maiores índices do mundo: possui cerca de 5 milhões de crianças e jovens, entre 5 e 17 anos de idade exercendo alguma atividade econômica (PNAD, 2001).

Ainda que o número de crianças brasileiras trabalhadoras venha diminuindo, a situação desses menores continua preocupante, pois geralmente encontram-se inseridos em atividades consideradas como as piores formas de trabalho - trabalho rural, em pedreiras, carvoarias, nos lixões, tráfico de drogas, entre outros (PNAD, 2001).

A incidência do trabalho infanto-juvenil no Brasil, assim como em vários países subdesenvolvidos ou em desenvolvimento, está intimamente ligada à pobreza das famílias, que vêem em suas crianças uma forma de ampliar sua renda.

Entretanto, a idéia de que a utilização de mão-de-obra infantil estaria reduzindo a miséria da família não procede. Esclarece José Paulo Chahad e Emylli Santos que, com essas prática, o que ocorre é exatamente o contrário:

o indivíduo que inicia sua atividade econômica precocemente não termina seus estudos ou sequer os inicia, e sem a formação educacional devida, limita suas possibilidades de emprego e não obtém qualificação necessária para futuros trabalhos com melhor remuneração, levando consequentemente à necessidade desse mesmo indivíduo, que trabalhou quando criança, ter os seus filhos trabalhando, para complementar sua renda familiar. Forma-se um verdadeiro ciclo da pobreza, onde o trabalho infantil de uma geração passada determina o mesmo nas gerações futuras (CHAHAD; SANTOS, 2006, p.108).

Ainda que 0 aspecto financeiro das famílias seja o principal fator para a precoce inserção de menores em atividades laborais, essa não é a causa exclusiva. 
Mesmo após três séculos, a mentalidade capitalista que aflorou na Revolução Industrial, ainda persiste, e agora, sob as vestes da globalização, o aumento da concorrência internacional, faz com que muitas empresas insistam em contratar mão-de-obra infantil, visando a diminuição de despesas (pois pagam salários inferiores, ainda que expressamente proibido), e o menor custo de seus produtos, para que vençam a concorrência (GRUNSPUN, 2002, p. 23).

Há também fatores como as características pessoais de cada indivíduo, que determinam o trabalho dos mesmos. Existem crianças, até mesmo com renda familiar suficiente para a manutenção e sustento sem necessidade de contribuição econômica, que, por decisão da família, ou por vontade própria, decidem adquirir independência financeira, ou mesmo que, não tendo qualquer interesse pelos estudos, optam por trabalhar (CHAHAD; SANTOS, 2006, p. 107).

Além disso, não raro persiste a idéia de que o trabalho é edificante, porque traz responsabilidades, noções de vida e crescimento àqueles que nele ingressam, mesmo que ainda muito jovens, além de retirá-los do ócio e afastá-los da criminalidade.

Todavia, ocorre que o trabalho precoce, como bem explica Erotilde Minharro, não educa nem profissionaliza, ao contrário, deixa as crianças expostas a ambientes perniciosos, prejudicando seu desenvolvimento físico, intelectual, moral e social (M INHARRO, 2003, p. 89).

Desse modo, deve-se conscientizar a sociedade de que o trabalho precoce é extremamente prejudicial a pessoas ainda em desenvolvimento, rechaçando-se a mentalidade de que o trabalho é virtuoso.

\section{0 papel da Organização Internacional do Trabalho - OIT}

Logo após a incorporação da Declaração de Filadélfia pela OIT, em 1946, esta passou a promover programas para a proteção da infância e da maternidade, com a finalidade de garantir iguais oportunidades educativas e profissionais (SÜSSEKIND, 2002, p. 501).

Nesse contexto, a OIT aprovou a Convenção n. 138, em 1973, complementada pela Recomendação n. 146, que unificou todas as Convenções anteriores que tratavam sobre a idade mínima de admissão ao emprego. 
A Convenção n. 138 estabelece a regra geral acerca do limite etário para os países ratificantes, dos quais o Brasil se inclui, prescrevendo que a idade mínima para a admissão ao emprego ou trabalho não deve ser inferior àquela quando cessa a obrigatoriedade escolar, não podendo, em qualquer hipótese ser inferior a 15 anos, exceto naqueles países em que a educação e desenvolvimento ainda não estiverem em nível de progresso adequado, hipótese em que se admite a realização do trabalho a partir de 14 anos (SÜSSEKIND, 2000, p. 399).

Tal Convenção foi aprovada pelo Congresso Nacional através do Decreto Legislativo n. 179/1999, e promulgado pelo Decreto n. 4.134/2002, que passou a vigorar no ordenamento jurídico brasileiro em 28 de junho de 2002.

A Recomendação n. 146 buscou concretizar os dispositivos trazidos pela Convenção n. 138, preceituando que, para cada país poder se posicionar quanto a idade mínima para 0 trabalho a ser adotada, medidas políticas e socioeconômicas devem ser adotadas para oportunizar melhores e mais empregos, diminuir a pobreza da população, desenvolver programas de bem-estar e seguridade social, proporcionar educação e formação profissional e possibilitar 0 acesso à saúde, visando a elevação progressiva da idade mínima para 0 trabalho para 16 anos (GRUNSPUN, 2002, p. 88).

Outra Convenção de extrema importância, instituída em 1999, foi a de n. 182, que trata da Proibição das Piores Formas de Trabalho Infantil. Nela instaurou-se o dever a todos países que a retificassem, de instituir medidas imediatas, a fim de erradicar todas as formas de escravidão ou práticas análogas, e todos demais trabalhos que possam vir a prejudicar a saúde, a segurança e a moral de crianças e adolescentes.

A Convenção n. 182 foi aprovada pelo Congresso Nacional por meio do Decreto Legislativo n. 178/1999, e promulgada através do Decreto n. 3.597/2000, entrando em vigor no ordenamento jurídico brasileiro em 2 de fevereiro de 2001.

Complementando a Convenção n. 182, a Recomendação n. 190 foi implementada para que fossem instituídos programas visando impedir a prática desses tipos de trabalho e para que os Estados membros identificassem e denunciassem a prática de tais atividades tidas como perigosas.

É nesse contexto que a OIT, através de suas Convenções e Recomendações, especialmente as que tratam da idade mínima para o trabalho e sobre quais são as piores 
formas de trabalho infantil, auxiliam no combate ao trabalho infanto-juvenil, fazendo com que os países participantes das mesmas atentem-se para essa questão, implementando políticas publicas, ações sociais e projetos visando a erradicação da exploração infantil e do trabalho adolescente irregular.

\section{Normas de proteção ao trabalho do menor no Brasil}

Limite de idade

A imposição de um limite etário para que adolescentes ingressem no mercado de trabalho é previsto pela Constituição Federal em seu art. 70, inciso XXXIII, e pela Consolidação das Leis do Trabalho, em seus arts. 402 e 403, os quais receberam nova redação após a Emenda Constitucional n. 20/98, que elevou a idade mínima para o trabalho de 14 para 16 anos, sendo autorizado o trabalho a partir dos 14 anos na condição de aprendiz, e vedado os trabalhos considerados perigosos, penosos, prejudiciais, realizados em período noturno, e em locais insalubres, para menores de 18 anos.

Essa mudança no limite de idade para admissão de menores trabalhadores, provocada pela EC $n .20 / 98$, causou bastante polêmica e foi muito debatida à época entre os juristas, mormente sua viabilidade diante da realidade socioeconômica brasileira, onde a desigualdade prevalece, e em que não raras vezes a renda dos adolescentes é essencial para a sobrevivência da família.

Aqueles que discordavam da elevação da idade mínima baseavam-se no fato de que a obrigatoriedade escolar se dá apenas até os 14 anos, pois, de acordo com o M inistério da Educação, o Estado tem o dever de proporcionar ensino público e gratuito apenas durante os anos do ensino fundamental. Para o ensino médio há apenas um princípio programático de "progressiva universalização", com metas para a educação que o Estado se compromete a alcançar ${ }^{3}$.

Em razão de o Estado não ter, ainda, obrigação em proporcionar o Ensino M édio a todos de forma gratuita, aqueles que condenavam a elevação da idade mínima, argumentavam que 0 adolescente que não conseguisse ingressar no ensino médio, ficaria

3 MINISTÉRIO da Educação. Ensino Médio. Disponível em: «ttp:// portal.mec.gov.br/seb/index.php?option=content\&task=view\&id=391\&ltemid=375>. Acesso em: 30 mar. 2008. 
sem freqüentar a escola, e também não poderia exercer atividade laborativa formal. Diante dessa falta de ocupação os menores acabariam sendo introduzidos no mercado informal, ou iniciariam uma vida criminosa e promíscua.

Ainda, juristas como Eduardo Saad, criticaram a mudança trazida pela EC n. 20/98, alegando que a realidade social e econômica do Brasil ainda não possibilita aos seus jovens condições suficientes a se manterem apenas com os estudos. Pelo contrário, exige que trabalhem para, ao menos, tentarem viver dignamente (SAAD, 1999, p. 188).

Por outro lado, os que enalteceram a alteração da idade mínima para dezesseis anos, inferiam que a Emenda Constitucional incorporou de forma acertada o princípio da proteção integral das crianças e adolescentes, previsto no art. 227 da Carta M agna.

Para estes, andou bem o legislador ao elevar a idade para ingresso no mercado de trabalho, por todos os fundamentos de ordem fisiológica, moral e de segurança que permeiam crianças e adolescentes, por sua condição especial. A idade conferida pela Emenda Constitucional considerou a higidez física e psicológica dos adolescentes, para sua correta formação e desenvolvimento, propiciando um maior espaço para a formação educacional do menor (MARTINS, A., 2002, p. 81).

A última corrente prevaleceu, e as novas regras trazidas pela referida Emenda Constitucional foram recepcionadas pelo ordenamento jurídico, incorporando-se a todos os textos legais que tratavam sobre 0 assunto.

Dessa forma, restou definido que é totalmente incapaz para o trabalho o menor de 16 anos, ainda que devidamente representado, salvo na condição aprendiz, que pode iniciar suas atividades aos 14 anos completos.

0 adolescente entre 16 e 18 anos é relativamente incapaz para o labor, pois, para tanto, depende de autorização dos pais ou responsáveis legais, carece de assistência em determinados atos como a quitação das verbas rescisórias, e não pode realizar certos tipos de trabalho, como o noturno, insalubre ou perigoso, os quais são proibidos até os 18 anos.

Deve-se salientar que, embora o contrato de trabalho dos menores de 18 anos deva se realizar mediante a assistência de seus responsáveis, estes apenas acompanham o menor, não podendo substituí-lo e contratar sem o mesmo, pois este deve, necessariamente, participar da contratação, legitimando-a, pois a força de trabalho a ser despendida será a 
dele. Além disso, a pessoalidade é requisito para estabelecer o vínculo laboral (MINHARRO, 2003, p, 54).

Nesse aspecto, a jurisprudência tem se firmado no sentido de dispensar a autorização quando da contratação do menor, se este possuir carteira de trabalho. Essa concessão aos que já possuem a CTPS ocorre porque a expedição da mesma condiciona-se à apresentação de declaração expressa dos pais ou responsáveis legais, assim, basta sua existência como prova da existência de tal outorga (NASCIM ENTO, A., 2007, p. 992).

A proibição para qualquer tipo de trabalho antes dos 16 anos de idade, e, para aqueles considerados perigosos, penosos, prejudiciais à formação moral e educacional, realizados no período noturno, ou em locais insalubres, antes dos 18 anos, justifica-se em fatores de ordem cultural, moral, fisiológico e de segurança (M ARTINS, S., 2007, p. 605), pois nessas faixas etárias, os menores encontram-se em pleno desenvolvimento físico e psicológico, o qual não deve ser interrompido nem prejudicado.

No entanto, para os casos em que, mesmo sendo proibido o trabalho de menores, estes exercerem atividades laborais, Ihes é devido todos os direitos trabalhistas e previdenciários, uma vez que, como determina a jurisprudência dominante, o contrato de trabalho daqueles totalmente incapazes para o trabalho, só é nulo a partir do momento em que assim é declarado.

Ou seja, a nulidade dos seus efeitos jurídicos, só se dá a partir de seu reconhecimento pela autoridade devida, de forma que a nulidade não produz efeitos retroativos, é ex nunc.

Nilson de Oliveira Nascimento explana que o menor não pode ser prejudicado, e nem é justo que o empregador seja beneficiado à custa alheia, pois o empregador não pode "devolver" ao empregado a prestação de seus serviços, de forma que a incapacidade absoluta conferida pelo legislador ao menor de 16 anos não tem a intenção de lesar a criança ou o adolescente, pelo contrário, visa protegê-los, proporcionando-os tempo para os estudos e convivência familiar. Assim, são devidos seus direitos trabalhistas e previdenciários (NASCIM ENTO, N., 2003, p. 153).

Nesses casos, além do dever de pagar todas as verbas trabalhistas, incluindo os respectivos adicionais, e efetuar as contribuições previdenciárias, o empregador que se utilizou indevidamente de mão-de-obra proibida deverá sofrer sanções de ordem pecuniária 
- multa no valor de um salário mínimo regional, cujo número de vezes a ser aplicada varia de acordo com o número de menores empregados em desacordo com lei. Entretanto, o dispositivo legal que prevê a multa (art. 434 da CLT) ressalva que a soma das multas não pode exceder a cinco vezes o salário mínimo, podendo, no entanto, dobrar no caso de reincidência.

Jornada de trabalho

A duração do tempo em que o empregado adolescente entre 16 e 18 anos de idade deve prestar serviço ou permanecer à disposição do empregador é regulada pela Consolidação das Leis do Trabalho, nos arts. 411 a 414.

Assim, com relação à jornada de trabalho aos menores, a legislação brasileira estabelece praticamente as mesmas regras que disciplinam a jornada dos trabalhadores adultos, o que pode ser constatado pelo art. 411 da Consolidação. Dessa forma, verifica-se que 0 inciso XIII do art. 70 da Constituição também se aplica aos trabalhadores adolescentes. A norma constitucional institui que a jornada de trabalho do menor é a mesma do maior, ou seja, 8 horas diárias e 44 horas semanais.

Todavia, diferentemente da jornada dos adultos, a dos adolescentes não admite prorrogação. Tal regra, se desrespeitada pelo empregador, não impede que o jovem que trabalhou em horas extraordinárias receba 0 adicional devido, pois essa norma visa preservar o menor, e não prejudicá-lo.

So mente em duas hipóteses, previstas expressamente na Consolidação, em seu art. 413, é que se admite a prorrogação de jornada do adolescente: compensação de horas ou em decorrência de força maior.

No primeiro caso, a duração diária do trabalho do menor pode ser prorrogada por até 2 horas, desde que previsto em acordo ou convenção coletiva, e que as horas a mais sejam compensadas pela diminuição destas em outro dia daquela mesma semana em que 0 menor laborou por um tempo maior, para não ultrapassar as 44 horas semanais, eis que tal regra tem caráter especial, em função de se tratar de menor trabalhador (MARTINS, S., 2007, p. 612). Nessa hipótese, a prorrogação da jornada de trabalho não gera direito à percepção de acréscimo salarial. 
$\mathrm{Na}$ hipótese de força maior, esta somente é aceitável se o trabalho do adolescente for imprescindível ao funcionamento da empresa, e pelo tempo máximo de 12 horas. Nesse caso, é devido o pagamento de adicional de $50 \%$ sobre a hora normal, eis que se trata de serviço extraordinário, e portanto, 0 art. 413, inciso II da CLT, que previa o acréscimo de apenas $25 \%$ sobre a hora normal, restou prejudicado em razão do art. 70 da Lei Maior ter previsto 0 adicional de 50\% (M ARTINS, S., 2007, p. 612).

Nesse caso, o trabalho extraordinário do menor pode ser realizado desde que tal situação seja comunicada ao Ministério do Trabalho, dentro de 48 horas. Além disso, o menor deve possuir atestado médico autorizando-o a prestar serviços, e tem o direito de usufruir 15 minutos de intervalo antes de iniciar a prorrogação do trabalho.

0 art. 412 da CLT garante ao menor o direito de intervalo para repouso, de no mínimo 11 horas, após cada período de trabalho, contínuo ou dividido em dois turnos.

Quanto ao intervalo intrajornada, com a finalidade de garantir a saúde e segurança do menor, é facultado à autoridade fiscalizadora determinar que o período de descanso durante a jornada seja desfrutado em outro local, que não o ambiente de trabalho.

Nesse contexto, o descanso semanal remunerado, de 24 horas consecutivas, e preferencialmente aos domingos, da mesma forma que é devido aos trabalhadores maiores (art. 67 da CLT), com muito mais razão, também é garantido aos adolescentes trabalhadores.

\section{Direitos trabalhistas}

Ao adolescente, assim como a quaisquer outros trabalhadores, é garantida a percepção de salário mínimo fixado em lei e nacionalmente unificado, como assegura o inciso IV do art. 70 da Constituição Federal. Dessa forma, restou proibido constitucionalmente, pelo inciso XXX do art. 70 da Carta Magna, a diferença salarial em razão de idade.

Diante da expressa vedação constitucional acerca das diferenças salariais por requisitos etários, revogou-se a Lei n. 5.274/67 que estipulava um salário mínimo específico para empregados menores (NASCIMENTO, A., 2007, p. 995), graduando a remuneração de acordo com a idade, permitindo-se assim a isonomia salarial em favor do adolescente, visando acabar com o efeito perverso da substituição de mão-de-obra adulta pela mais barata do adolescente (NASCIM ENTO, N., 2003, p. 143). 
Assim como todos os empregados, ao menor trabalhador também é garantido 0 direito ao repouso semanal remunerado, o pagamento de salários em feriados, a gratificação do décimo terceiro salário, férias e aviso prévio.

As férias anuais remuneradas também são reguladas, em sua grande parte, pelas mesmas regras que tratam sobre as férias dos trabalhadores adultos, sendo que 0 tratamento jurídico igualitário consiste na contagem do período aquisitivo, período concessivo, comunicação, pagamento, duração, bem como a perda ao direito de férias (NASCIM ENTO, N., 2003, p. 141).

A diferença reside no gozo das férias pelos menores, pois estes não podem usufruílas de modo fracionado, estas são concedidas de uma só vez, em um único período, e, sendo o menor também estudante, deverá usufruí-las no mesmo período das férias escolares (GOMES; GOTTSCHALK, 2007, p. 424).

Ainda, na hipótese de membros da família do menor laborarem no mesmo estabelecimento, é possível que todos gozem suas férias quando o menor assim o fizer, durante as férias da escola.

Quanto ao aviso prévio dado pelo adolescente trabalhador, o posicionamento jurisprudencial majoritário reside na validade da concessão do mesmo, sem assistência dos pais ou responsáveis.

O fundamento para tanto se encontra no fato de que, uma vez portador da carteira de trabalho, presumível é a autorização para prestação de serviços pelo menor, e se the é permitido celebrar contrato de trabalho, também está autorizado a desfazê-lo, por vontade própria (NASCIM ENTO, N., 2003, p. 147).

Assim, é considerada válida a comunicação do aviso prévio formulada diretamente pelo empregado menor, sendo que, essa validade somente estará limitada diante da constatação de vício de consentimento, o que acarretará a nulidade do ato.

\section{Prescrição}

0 art. 169 do Código Civil, dispõe que a prescrição não corre contra os absolutamente incapazes. A Consolidação foi mais abrangente, estabelecendo em seu art. 440 , que nenhum prazo prescricional corre contra os menores de dezoito anos, constituindo 
a menoridade, causa impeditiva de prescrição contra o menor, pois a idade atua como causa suspensiva do prazo prescricional.

Assim, em relação aos trabalhadores menores de 18 anos não há que se falar em prescrição. Esta só se inicia quando atingirem a maioridade trabalhista, ou seja, aos dezoito anos.

Nas hipóteses em que o menor venha a Juízo como sucessor de empregado falecido, o entendimento majoritário, inclusive sustentado pelo Tribunal Superior do Trabalho é de que, no momento em que há o falecimento e o menor passa a integrar a lide, a idade, desde que o menor tenha menos de 16 anos, como causa suspensiva da prescrição, impede que o prazo prescricional flua.

De outro turno, há a inteligência, não preponderante, de que o art. 440 da CLT aplica-se apenas e tão somente aos trabalhadores menores, uma vez que se encontra no capítulo 'Da Proteção do Trabalhado do Menor', e por isso, nos casos em que os menores são partes na Reclamatória Trabalhista como herdeiros, e não como empregados, de modo que o espólio constituído por herdeiros deve-se fazer representar por pessoa capaz, e portanto, plenamente aplicável o prazo prescricional.

O tema sobre a incidência prescrição para créditos trabalhistas, relativos a herdeiros menores, ainda é divergente. No entanto, prevalece 0 entendimento de que 0 prazo prescricional não deve atingir tais créditos, sendo plenamente aplicável o art. 440 da CLT também nesses casos, uma vez que envolvem menores, e estes devem ser protegidos.

Esse é o entendimento do Tribunal Superior do Trabalho, que também defende a aplicação do referido artigo da CLT para herdeiros menores.

\section{Aprendizagem}

A Constituição Federal, ao prever a garantia da proteção integral às crianças e adolescentes, juntamente com o Estatuto da Criança e do Adolescente, particularmente no campo do trabalho, estabelecem o direito à profissionalização como conseqüência da proteção integral às crianças e adolescentes.

É nesse contexto de proteção especial às crianças e adolescentes, onde se encontram, dentre outros, o direito à educação e à profissionalização, que se insere a 
aprendizagem do menor, a partir dos 14 anos de idade, e que é possibilitada através de entidades de formação técnico-profissional.

Contrato de aprendizagem - condições, objetivos e possibilidades

A contratação de aprendizes é hoje regulada pelo Decreto n. 5.598/2005, o qual regulamenta a Lei n. 10.097/2000, e prevê em seu art. 3o o que vem a ser um contrato de aprendizagem:

Art. 30 Contrato de Aprendizagem é o contrato de trabalho especial, ajustado por escrito e por prazo determinado não superior a dois anos, em que o empregador se compromete a assegurar ao aprendiz, inscrito em programa de aprendizagem, formação técnico-profissional metódica compatível com o seu desenvolvimento físico, moral e psicológico, e o aprendiz se compromete a executar com zelo e diligência as tarefas necessárias a essa formação.

A aprendizagem é uma das primeiras fases de um processo de profissionalização, e se conceitua como um ensino com alternância de teoria e prática, metódico (com operações ordenadas de acordo com um programa em que se passa do mais simples para o mais complexo), sob a orientação de um responsável, e em ambiente adequado - pessoal docente, aparelhagem, equipamento (OLIVEIRA, 2006, p. 215).

Resumidamente, pode-se dizer que a aprendizagem é o processo de formação técnico-profissional a que se submete o menor, por prazo certo, com um método para seu desenvolvimento, em que exista uma alternância entre a teoria e a prática, para que o jovem possa assimilar todo o conhecimento que lhe está sendo proporcionado. Objetiva a capacitação do jovem para um ofício, arte ou função, visando uma colocação no mercado de trabalho, sem que sua formação escolar básica seja prejudicada (M ARANHÃO et al., 2002, p. 996).

Conforme estabelece o caput do art. 428 da Consolidação das Leis do Trabalho, é necessário que o aprendiz tenha entre 14 e 24 anos de idade, sendo que, sua contratação deve priorizar os adolescentes entre 14 e 18 anos de idade, exceto nas hipóteses em que é proibido o trabalho de menores.

O limite máximo etário foi elevado de 18 para 24 anos pela lei n. 11.180/05, visando a ampliação do acesso de uma maior parcela da juventude brasileira à qualificação social e 
profissional, oportunizando-lhes inserção no mercado de trabalho, conforme a exposição de motivos da referida lei. Além disso, é uma forma de tentar qualificar os jovens nessa faixa etária que não conseguem seu primeiro emprego (MARTINS, S., 2007, p. 617).

Para que o contrato de aprendizagem seja válido é necessário a anotação na Carteira de Trabalho e Previdência Social, a inscrição do jovem em programa de aprendizagem e matrícula em escola para conclusão do curso de ensino fundamental, além do cumprimento dos objetivos da aprendizagem (NASCIM ENTO, A., 2007, p. 998).

Caso tais condições não forem obedecidas, o contrato de aprendizagem será reputado nulo, e restará configurada a fraude à lei trabalhista (art. 9o da CLT), implicando a sua conversão em contrato de emprego regido pela CLT, acarretando uma série de conseqüências, como o direito do empregado receber a diferença da alíquota do FGTS, de $2 \%$ para $8 \%$, diferenças do valor do piso salarial da categoria, além do aviso prévio e multa de $40 \%$ do FGTS (DALLEGRAVE NETO, 2007, p. 372).

A duração desse tipo de contrato, consoante 0 §3ㅇ do art. 428 da CLT, não pode ultrapassar dois anos. Por essa razão é considerado contrato por tempo determinado, ainda que não disponha sobre serviços transitórios e nem seja um contrato de experiência, pois 0 legislador assim precisou de forma expressa no caput do artigo mencionado (M INHARRO, 2003, p. 81).

O contrato de aprendizagem pode ser prorrogado por apenas uma vez, desde que não ultrapasse os dois anos previstos para sua duração em razão do art. 451 da CLT. Ou seja, mesmo com a prorrogação do contrato, o tempo total da aprendizagem deve estar inserida nesses dois anos, sob pena de se configurar como um contrato de trabalho comum por prazo indeterminado (M ARTINS, S., 2007, p. 615).

Diante da importância da aprendizagem, especialmente diante do atual mercado de trabalho, em que só fazem parte dele aqueles que são profissionais, e, qualificados para tanto, a lei que regula a aprendizagem prevê a obrigação das empresas de matricular e empregar aprendizes no percentual de 5\% a 15\% do total de trabalhadores, em funções que demandem formação profissional.

Não obstante tal previsão, inexiste na lei qualquer lista de ofícios complexos sujeitos à aprendizagem, assim, utiliza-se a Instrução Normativa SIT no 26, de dezembro de 2001, a qual estabelece que, para definir quais as funções que demandam formação técnico- 
profissional deve-se considerar a Classificação Brasileira de Ocupações (esta também prevista pelo Decreto n. 5.598/2005, em seu art. 10), e outros fatores nela expressamente previstos. (SOARES, 2007, p. 16).

Como forma de suprir a lacuna existente em relação ao rol de atividades que demandam formação profissional, o M inistério do Trabalho e Emprego, também através da IN SIT 26/2001, elaborou alguns critérios de exclusão para o cálculo das cotas que devem ser proporcionadas aos aprendizes.

Assim, funções que exijam formação técnica ou superior; cargos de direção e de gerência ou de confiança; funções cujo exercício requeira licença ou autorização vedadas para menores de 18 anos; atividades desenvolvidas em ambientes que comprometam a formação moral do aprendiz, dentre outras, ainda que demandem formação técnicoprofissional não podem ser exercidas por aprendizes (NASCIM ENTO, N., 2003, p. 123).

Estão isentos de contratar aprendizes as empresas cujas frações de unidade no cálculo da percentagem de aprendizes seja inferior a um, as microempresas e empresas de pequeno porte (art. 11 da Lei n. 9.841/99), assim como as entidades sem fins lucrativos que tenham por objetivo a educação profissional (art. 429-A §1ㅇ da CLT).

Nos casos em que a contratação de aprendizes se der por empresas públicas ou sociedades de economia mista, 0 art. 16 do Decreto n. 5.598/05 disciplina que esta deve ocorrer de forma direta, através de processo seletivo mediante edital, respeitando-se os princípios da Administração Pública.

Os centros de formação profissional, que mantém cursos de aprendizagem são aqueles do Serviço Nacional de Aprendizagem, o chamado Sistema " $S$ ", entretanto, quando estes não possuírem vagas suficientes ou não oferecerem determinados cursos, escolas técnicas de educação e entidades sem fins lucrativos, também poderão proporcionar esse tipo de formação.

\section{Extinção do contrato de aprendizagem}

A extinção do contrato de aprendizagem decorre de duas hipóteses, assim previstas no caput art. 433 da Consolidação das Leis do Trabalho, quais sejam: pelo termo da aprendizagem, ou seja, findo o prazo máximo de dois anos dessa espécie de contrato ou 
quando estipulado prazo inferior a este, ou, ao completar 24 anos de idade, ainda que 0 contrato não tenha chegado ao fim (M ARTINS, S., 2007, p. 622).

A única exceção quanto a impossibilidade de se enquadrarem na condição de aprendizes ao ultrapassarem os 24 anos de idade, se dá com relação aos portadores de deficiência. A estes não se aplica a limitação de idade máxima para serem contratados como aprendizes, na forma do $\$ 50$ do art. 428 da CLT.

Outras formas de rescisão do contrato de aprendizagem são as chamadas hipóteses de extinção antecipada, e estão previstas nos incisos do art. 433 da Consolidação. Compreendem causas de extinção antecipada do contrato de aprendizagem o desempenho insuficiente ou inadaptação do aprendiz, cometimento de falta disciplinar grave, ausência injustificada à escola que comprometa seu ano letivo, ou o pedido do aprendiz para deixar o trabalho.

As hipóteses de rescisão contratual por justa causa do aprendiz encontram-se no inciso II (falta disciplinar grave) e no art. 482 da Consolidação, e, somente nesses casos 0 empregador fica dispensado do pagamento de 13ํsalário, férias proporcionais e liberação de fundo de garantia. Em todos os demais casos de extinção do contrato de aprendizagem tais verbas serão devidas, exceto quando 0 adolescente, por sua vontade o rompe, situação em que o FGTS não será liberado (M ARTINS, A., 2002, p. 91).

0 desempenho insuficiente, a inadaptação do aprendiz ou a ausência injustificada à escola autorizam a cessação antecipada do contrato, mas sem justa causa.

Por força do $§ 2^{\circ}$ do art. 433 da CLT, as indenizações previstas nos arts. 479 e 480 da CLT não são devidas nesses casos de extinção antecipada do contrato de aprendizagem.

Jornada de trabalho dos aprendizes

A jornada de trabalho do aprendiz, como já exposto, deve compreender também as aulas teóricas para formação técnico-profissional do aprendiz.

Não pode ultrapassar seis horas diárias para aqueles que, comprovadamente estejam matriculados e freqüentando as aulas do ensino fundamental.

De acordo com o que dispõe 0 art. 432 do CLT, também é vedado 0 regime de compensação de horas e a prorrogação de jornada, ainda que presentes as hipóteses dos incisos I e II do art. 413 da CLT (compensação prevista em acordo ou convenção coletiva e 
em caso de força maior). No entanto, caso se verifique que o aprendiz tenha ultrapassado os limites legais de sua jornada, o empregador deverá remunerar-Ihe tais horas como extras, acrescidas de $50 \%$.

Para aqueles aprendizes que já tenham completado o ensino fundamental, o limite de seis horas poderá ser elevado para oito horas por dia, incluindo-se da mesma forma as horas destinadas à aprendizagem teórica.

\section{Direitos trabalhistas dos aprendizes}

Ao aprendiz é devido o salário mínimo hora, caso não exista condição mais favorável à sua remuneração. Essa garantia é prevista pelo $2^{\circ}$ do art. 428 da Consolidação das Leis do Trabalho, que derrogou 0 art. 80 da mesma legislação, dispositivo este que previa a remuneração ao aprendiz de apenas meio salário mínimo para a primeira fase da aprendizagem, e após, dois terços do salário mínimo, numa segunda fase (NASCIM ENTO, N., 2003, p. 120).

Isso porque, em consonância com 0 art. 70 da Constituição, não é permitida a diferença salarial por motivo de idade (inciso XXX), e é assegurado ao trabalhador a percepção de um salário mínimo, fixado em lei e nacionalmente unificado (inciso IV).

A remuneração deve ser efetuada tanto pelas horas trabalhadas na empresa quanto por aquelas destinadas às aulas teóricas para sua formação técnico-profissional, vez que, todas essas horas devem ser computadas como jornadas de trabalho (DALLEGRAVE NETO, 2007, p. 374).

Quanto ao Fundo de Garantia por Tempo de Serviço devido ao menor aprendiz, de acordo com 0 art. 24 do Decreto, que determina a aplicação do $\S 70$ do art. 15 da Lei $n$. $8.036 / 90$, os contratos de aprendizagem terão a alíquota de depósito reduzida para $2 \%$ sobre o valor da remuneração do aprendiz.

Assim como a qualquer trabalhador menor, o aprendiz também tem direito a usufruir de suas férias no mesmo período das férias escolares, e de forma não fragmentada. 


\section{Legitimados na concretização da proteção aos menores trabalhadores}

Um dos mais importantes órgãos responsáveis pela preservação dos direitos dos menores é o M inistério Público do Trabalho, que detém legitimidade para atuar como parte, propondo ações civis públicas para defesa dos menores trabalhadores - quando estes estiverem exercendo trabalhos proibidos, e para punição daqueles empregadores que se utilizaram de mão-de-obra infantil, nos casos em que restarem frustradas as tentativas de eliminar a contratação de mão-de-obra infantil, de forma amigável.

Da mesma forma, nos trabalhos permitidos, em que adolescentes acima dos 16 anos de idade exerçam atividades em condições que não prejudiquem sua formação fisiológica e psíquica, o M inistério Público do Trabalho pode atuar como representante do jovem trabalhador, para pleitear verbas devidas que não Ihe foram pagas corretamente, quando o menor não puder ser representado por seus pais ou responsáveis, como estabelece 0 art. 793 da CLT.

Não obstante a existência de penalidades previstas aos empregadores que não observarem as normas de proteção aos trabalhadores menores, assim como a proibição de trabalho pelos adolescentes antes dos 16 anos, as Procuradorias do Trabalho buscam, antes de tudo, realizar um trabalho preventivo, através de projetos para conscientização das famílias, dos empregadores e de toda a sociedade, sobre a prejudicialidade que o trabalho precoce pode representar às crianças e adolescentes.

O Ministério do Trabalho e Emprego também tem função especial no combate ao trabalho infantil e adolescente irregular. Para tanto, tem como principal órgão para the auxiliar na verificação do bom cumprimento das normas de proteção dos trabalhadores em geral, e, em especial, garantindo o efetivo cumprimento das normas laborais de proteção às crianças e aos adolescentes, as Delegacias Regionais do Trabalho.

Ainda, o M inistério do Trabalho criou Núcleos de Erradicação do Trabalho Infantil e de Proteção ao Trabalho do Adolescente nos estados da Federação que, com o apoio das Delegacias, procuram verificar em quais regiões 0 trabalho infantil se faz mais presente, reforçando nestas as ações de combate à tais práticas.

Também instituiu em nível nacional a Comissão Nacional de Erradicação do Trabalho Infantil no ano de 2002 - a CONAETI, que se baseou no compromisso assumido 
pelo Brasil, quando assinou as Convenções n. 138 e 182 da Organização Internacional do Trabalho, em observar uma idade mínima para o trabalho e atentar-se para a existência das piores formas de trabalho infantil, sumprimindo-as.

Desta forma, atribuiu-se à CONAETI, o encargo de regulamentar as referidas Convenções da OIT, adequando-as ao ordenamento jurídico brasileiro, e elaborando meios para aplicação dos dispositivos trazidos por tais Convenções, além do dever de elaborar um plano nacional para o combate ao trabalho infantil.

Um outro órgão essencial no auxílio para o combate à exploração infanto-juvenil é o conselho tutelar, órgão representativo da sociedade, permanente, autônomo e não jurisdicional, que atua, juntamente com a família e o Estado, para a concretização da proteção integral e garantia dos direitos fundamentais das crianças e adolescentes (ELIAS, 1994, p. 112).

Assim, nos casos em que o Conselho Tutelar noticia situações de trabalho infantojuvenil em desacordo com as normas que tratam do assunto, deve sempre levar ao conhecimento do Ministério Público do Trabalho ou das Delegacias Regionais do Trabalho, para que tais órgãos tomem as devidas providências - procedimentos investigatórios, assinatura de termo de compromisso pelo empregador ou empresa infratora e aplicação das respectivas penalidades.

o Conselho Tutelar, em seu dever de contribuir para a garantia e proteção dos direitos dos menores, também é responsável pela fiscalização de empresas e empregadores individuais que assinarem o termo de compromisso, pois, se constatar o descumprimento do mesmo, deverá comunicar à Delegacia Regional do Trabalho, para que esta proceda à cobrança das multas.

Assim, o Conselho Tutelar possibilita que, através de seus conselheiros, a sociedade efetivamente ajude a zelar pelos direitos das crianças e adolescentes, como prevê 0 art. 227 da Constituição, incluindo-se também a proteção aos menores trabalhadores, pois, embora esta matéria não seja de sua competência específica, como órgão garantidor dos direitos de crianças e adolescentes, deve auxiliar no combate á exploração infantil e trabalhos irregulares realizados por adolescentes.

Por fim, é necssário ressaltar a importância das empresas no contexto atual quanto à proteção aos menores trabalhadores, tendo em vista a função social que detêm. 
Por serem espécie de propriedade privada, a concepção absoluta da propriedade/ empresa, em que o direito de uso e gozo ocorre de forma absoluta e egoísta, sem levar em conta o interesse da sociedade, deve ser rechaçado (FERREIRA FILHO, 2008, p. 361).

A função social da empresa engloba a geração de empregos, o que vincula também o amparo do jovem trabalhador, seja através de programas de aprendizagem, pelos quais possibilita-se ao adolescente uma formação técnica e consequente melhoria nas chances de alcançar no futuro uma profissão e um trabalho mais vantajoso, seja através do cumprimento das leis de proteção aos menores trabalhadores.

Dessa forma, cabe às empresas observarem o princípio da proteção integral de crianças e adolescentes, não permitindo a contratação de menores de 16 anos, e atentandose para as funções dos jovens entre 16 e 18 anos de idade, para que não Ihes prejudique a formação e desenvolvimento físico, psíquico e moral.

Além disso, as empresas devem motivar o aprendizado, através da contratação de aprendizes, para que estes jovens adquiram uma formação técnica-profissional que thes auxilie no futuro, facilitando seu ingresso no mercado de trabalho.

\section{Conclusão}

O estudo apresentado evidenciou a importância das normas de proteção ao trabalho do menor, bem como da OIT e dos responsáveis pela sua aplicação, diante da prejudicialidade que 0 trabalho pode acarretar a crianças e jovens ainda em desenvolvimento.

Pôde-se constatar que a legislação brasileira, ao tratar da proteção ao trabalho do menor, seguiu a tendência do Direito Internacional, e da análise destas normas, pôde se verificar que o Brasil possui uma notável regulamentação jurídica, bastante minuciosa, que, já na Constituição Federal prevê expressamente o objetivo de eliminar o trabalho antes dos 16 anos de idade, salvo na condição de aprendiz, bem como proibir a menores de idade 0 trabalho insalubre, perigoso, penoso, noturno, enfim, qualquer tipo de trabalho que prejudique o correto desenvolvimento físico e mental de crianças e adolescentes.

No mesmo sentido, a CLT, o ECA e a Lei de Aprendizagem, estipulam aos jovens trabalhadores proibições a certos tipos de trabalho, direitos individuais e trabalhistas, além de penalidades àqueles que não os cumprem. Também visam propiciar aos jovens 
oportunidades de formação técnico-profissional, garantindo-Ihes uma qualificação profissional para Ihes auxiliar na obtenção de um futuro emprego.

Embora todo esse aparato legislativo, restou evidenciado que, dentre outras causas para o trabalho infanto-juvenil, a realidade econômico-financeira de grande parte das famílias brasileiras, é a principal causa para que as crianças insiram-se em atividades econômicas. Ademais, essa situação persiste em razão da deficiente fiscalização do Poder Público.

Concluiu-se que não são as normas de proteção às crianças e adolescentes que se apresentam falhas, o que falta é a concretização das mesmas, pois a legislação é apenas 0 início das medidas de tutela desses menores.

É necessária a conscientização de toda a sociedade sobre quão prejudicial é um trabalho precoce, além de ser imprescindível que o Poder Público cumpra e faça cumprir todas essas normas, realizando intensivas fiscalizações, por meio do M inistério do Trabalho e Emprego, do Ministério Público do Trabalho, das Delegacias Regionais do Trabalho, contratando e incentivando a ações dos Auditores-Fiscais do Trabalho, nas áreas onde a exploração de mão-de-obra infantil apresenta-se mais freqüentes.

Assim, somente com ação conjunta de sociedade, empresas e governo, este último com a adoção de efetivas políticas públicas e projetos de incentivo à educação e auxilio às famílias necessitadas, de forma a realmente possibilitar 0 alcance dos objetivos pelos quais foram criados, e não meras estratégias eleitoreiras, é que se poderá atingir a finalidade das normas de proteção aos menores, tornando-as eficazes no combate ao trabalho infantojuvenil.

\section{Referências}

BARROS, Alice M onteiro de. Curso de Direito do Trabalho. 2. ed. São Paulo: LTr, 2006.

BRASIL. Decreto-Lei n. 5.452, de 10 de maio de 1943. Aprova a Consolidação das Leis do Trabalho. Brasília, DF, 1943.

. Decreto n. 5.598, de 1o de dezembro de 2005. Regulamenta a contratação de aprendizes e dá outras providências. Brasília, DF, 2005.

. Lei n. 8.069, de 13 de julho de 1990. Dispõe sobre o Estatuto da Criança e do Adolescente, e dá outras providências. Brasília, DF, 1990. 
. Lei n. 10.097, de 19 de dezembro de 2000. Altera dispositivos da Consolidação das Leis do Trabalho - CLT. Brasília, DF, 2000. 1988. . Constituição (1988). Constituição da República Federativa do Brasil. Brasília, DF,

CHAHAD, José Paulo Zeetano; SANTOS, Emylli Helmer. O Trabalho Infantil no Brasil: evolução, legislação e políticas visando sua erradicação. Revista de Direito do Trabalho, São Paulo, v. 32, n. 124, p. 95-122, out./dez. 2006.

CURY, M unir (Coord.). Estatuto da Criança e do Adolescente Comentado. 8. ed. São Paulo: Malheiros, 2006.

DALLEGRAVE NETO, José Affonso. Contrato de Trabalho Especial de Aprendizagem. Revista de Direito do Trabalho, São Paulo, v. 33, n. 128, p. 367-385, out./dez. 2007.

ELIAS, João Roberto. Comentários ao Estatuto da Criança e do Adolescente. São Paulo: Saraiva, 1994.

FERREIRA, José Carlos. Trabalho Infantil e a Luta contra a M iséria. Disponível em: বhttp://www.oitbrasil.org.br/news/artigos/ler_artigos.php?id=661>. Acesso em: $29 \mathrm{fev}$. 2008.

FERREIRA FILHO, M anoel Gonçalves. Curso de Direito Constitucional. 34. ed. São Paulo: Saraiva, 2008.

GOM ES, Orlando; GOTTSCHALK, Elson. Curso de Direito do Trabalho. 18. ed. Rio de Janeiro: Forense, 2007.

GRUNSPUN, Haim. O Trabalho das Crianças e dos Adolescentes. São Paulo: LTr, 2000.

INSTITUTO Brasileiro de Geografia e Estatística. Pesquisa Nacional por Amostragem de Domicílios - PNAD 2001 e 2004. Disponível em:

বhttp://www.ibge.gov.br/texto/pnadcoment4.html>. Acesso em: 27 jan. 2008.

M ARANHÃO, Délio et al. Instituições de Direito do Trabalho. São Paulo: LTr, 2002. v. 2.

M ARTINS, Adalberto. A Proteção Constitucional ao Trabalho de Crianças e Adolescentes. São Paulo: LTr, 2002.

M ARTINS, Sérgio Pinto. Direito do Trabalho. 23. ed. São Paulo: Atlas, 2007.

M INHARRO, Erotilde Ribeiro dos Santos. A Criança e o Adolescente no Direito do Trabalho. São Paulo: LTr, 2003. 
M INISTÉRIO da Educação. Ensino Médio. Disponível em:

http://portal.mec.gov.br/seb/index.php?option=content\&task=view\&id=391\&ltemid=375.

Acesso em: 30 mar. 2008.

M INISTÉRIO do Trabalho e Emprego. Comissão Nacional de Erradicação do Trabalho Infantil CONAETI. Disponível em: «ttp:// www.mte.gov.br/trab_infantil/conaeti.asp>. Acesso em: 20 abr. 2008.

M INISTÉRIO Público do Trabalho. Trabalho Infantil. Disponível em:

বttp://www.pgt.mpt.gov.br/pgtgc/ >. Acesso em: 15 mar.2008.

NASCIM ENTO, Amauri M ascaro. Curso de Direito do Trabalho. 22. ed. São Paulo: Saraiva, 2007.

NASCIM ENTO, Nilson de Oliveira. M anual do Trabalho do Menor. São Paulo: LTr, 2003.

SAAD, Eduardo Gabriel. Trabalho do M enor e a Emenda Constitucional n. 20/98. Suplemento Trabalhista LTr, São Paulo, v. 35, n. 038/99, p. 187-194.

SOARES, Lirian Sousa. M enor Aprendiz. Obrigação de Contratação. Limites Legais. Revista IOB Trabalhista e Previdenciária, v. 17, n. 214, p. 16-19, abr. 2007.

SÜSSEKIND, Arnaldo. Curso de Direito do Trabalho. Rio de Janeiro: Renovar, 2002. . Direito Internacional do Trabalho. 3. ed. São Paulo: LTr, 2000. 